\title{
Research on the Value and Molding of Humanistic Spirit in University Library
}

\author{
Yingpei Wang \\ Library of Jilin Agricultural University, Changchun, Jilin, China, 130000
}

\begin{abstract}
In the constant pursuit of scientific progress, building a humanistic spirit of the university library has become the major institutions of higher learning and even is an important part for social and cultural progress. The humanistic spirit is not only the development direction of university libraries, but also the "place" of higher education, teaching and scientific research in university libraries, and can promote the humanistic spirit to overcome the limitations of modern information technology. Reshaping the university libraries with humanistic spirit will have important social significance.
\end{abstract}

Keywords: humanistic spirit, university library, value and molding

\section{Introduction}

With the deepening of the popularization of higher education in China, the university library shoulders the mission of harmonizing with the development of higher education. Compared to solid professional knowledge, contemporary college students are missing a high humanistic spirit, noble moral sentiments, due social responsibility and the correct values. As a treasure house of knowledge, the library and information center of library and library, its unique humanistic environment and humanistic spirit, it is bound to exert a subtle influence on the establishment of correct outlook on life, the cultivation of moral character and the edification of sentiment.

The university library is the school document information center, is the academic service organization, is the teaching and research inseparable important constituent. In the rapid development of science and technology, university 
library service from the traditional model to the digital, intelligent transformation, in this huge transition emerging many new issues. Among them, the service of university library and the shaping of humanistic spirit have become one of the important subjects in recent years. In this paper, how to better shape the university library services and humanistic spirit for further discussion.

\section{The definition of library humanistic spirit}

Library humanistic spirit is originally formed in Western society. China's scholars from the 20th century, began to pay attention to 80 years, and gradually reach a consensus. Scholars generally believe that the humanistic spirit of the library is in the library practice and theoretical research in the people-oriented, attention to the value of human existence, to meet human needs, to achieve human values, the pursuit of human development, humanistic care for humanity to create beauty And harmony. The core of the humanistic spirit and the end result are humanistic care. Humanistic care in the library to create a humane atmosphere, into the human emotions, understanding readers, concerned readers, respect for readers, protect readers, promote the humanistic spirit. This paper will be the main readers of the library are defined as college students. Therefore, the core of humanistic care is to understand the students, care for students, respect for students, love students. Help students to establish the correct belief, improve the student's spiritual world and moral personality, so that students in a relaxed and pleasant environment to learn, live, and gradually realize the individual socialization.

\section{The university library services and humanistic spirit}

Since the beginning of the new century, the development trend of the digital libraries in our country has been cooled by the environmental impact of the slow development of the global digital library. The problems brought by the information technology have caused the library theorists to rethink the value of the humanistic spirit, Humanistic philosophy began to recover. It is gratifying that the humanistic spirit is gradually implemented in the library services, many university libraries have been in practice to promote the library services, the humanistic philosophy. Such as: South China Normal University Library, "the reader first, service first" service concept for the library, a substantial increase in the opening hours, the use of open-drop service, divided into eight disciplines Museum, each subject hall with a The subject librarian with the deep theoretical knowledge of the subject is engaged in a more personalized and characteristic deeper information retrieval and information consultation service, which can guide the readers deeper and deeper and facilitate the retrieval of books and periodicals at all levels. Shenzhen University Library opened a new admission training, the creation of "modern university library use" courses for freshman students elective, and the other with a help desk, in the use of the library when in 
trouble, specifically with business consulting phone And E-mail; South China Agricultural University Library services in the reader even more humane, they create a harmonious personalized service for the reader environment, which is a humanistic environment that contains the building environment, aesthetic taste of the rich indoor layout, creating Humane care of the service concept, they all read the library at the end of the table and the foot of the wall with information access points and power supply for the convenience of readers with their own notebook computers, in the reading area, shelf edge placed a lot of green ornamental plants, In the glass window and glass wall affixed with a green sunscreen, and posted a warm prompt language, so that readers read the heart is very comfortable, the implementation of open management, the reader can carry free access, and allows the book comes with a short time Lend, extend the opening hours of 85 hours per week. The library adheres to the tenet of "Readers First, Serve and Educate People" and gives full play to its educational, service, academic and social functions. All the staff regards the readers' satisfaction as the standard of work, smiling service face. Above all these practices, fully embodies the university library to the reader's humane care.

\section{The construction of university libraries, the important value of the human spirit}

From the long-term social development process in China, Confucius as the representative of the Confucian educational thought, strongly advocated "benevolence" as the core of the traditional humanistic spirit, and science and democracy as the core of modern scientific doctrine has become China's social development A subject. One of the manifestations of modern scientific spirit in college libraries is advocating modern information technology. In the era of large data, attention is paid to the construction of digitized, intelligent and networked libraries. While pursuing scientific progress, the construction of humanistic spiritual core University libraries make it become an important part of higher education institutions and even social and cultural progress. The spirit of the human spirit in the library work practice and theoretical research process, embodied in the spirit of the reader to meet the needs of the reader is the psychological needs of the reader, so that the spirit of the humanities truly become a modern university library logo and core services, So that the humanistic values of the spirit of modern university libraries become the core of professional and academic concern.

Therefore, the Chinese and foreign experts on the future of university libraries have described this spirit, the future of the university library is no longer limit the age of the reader level, cultural level, identity, become the new national education system is an important part of the extensive provision of valuable and meaningful Cultural leisure and learning opportunities, which is a clear manifestation of social and democratic progress, pay attention to human needs, human 
development, to create beauty and harmony will increasingly become the direction of library development.

In recent years, due to the continuous enrollment of colleges and universities in China, the popularization of higher education has made our country's higher education realize leaps and bounds. The university library is not only an important auxiliary department of education, teaching and scientific research in various institutions of higher learning, but also a true reflection of the academic and cultural level of each university. Literature building, the number of collections, information technology and so on become the major institutions of evaluation and measurement standards. Teachers, students in the teaching, scientific research not only from the library access to all kinds of academic information, literature collection, it is teachers and students to develop academic vision, learn extra-curricular knowledge nutrition, "back garden" to better carry forward the humanities, In the service, more enough to the reader's needs in the first place, to provide comprehensive, diversified services to enable readers to fully appreciate the library itself is distributed by the scholarly, humane atmosphere, feel the librarian Of humanistic care. So that students in just a few years to accept the process of higher education, experience and nurture the humane spirit of care in the institutions of higher learning among students to improve the future of personal culture, scientific research capabilities to complete the university library as an important teaching auxiliary department tasks.

\section{The study of humanistic spirit in university libraries}

The outdoor environment is a contrast to the library building, but also to the cultivation of the reader's mind. Layout should highlight the green concept, return to nature is the needs of the times, is a necessary condition for modern libraries, but also a refraction of the humanistic spirit. In this environment, we recognize that students are the masters of life, and to students to open a skylight, to the individual an open growing environment, give them the right to speak, so that individuals can be in such a value space for free choice And real experience, so that they actively participate in and build a modern society and their generation of moral system. Students not only learn knowledge here, but also in the subtle inspiration among the ideas, cultivate sentiment, beautify the mind, thus completing the ideal personality shape. Students also have a rich moral experience, the mind can become filled, the mentality becomes stable, only the inner peace of freedom and pure, so as to show enthusiasm and reason.

The interior decoration is one of the important means to express the affinity of university library. Beautify the indoor environment is an important way to create a library humanistic atmosphere. Indoor greening should not mediocrity, disorders and messy. Green plants not only enable readers to lift fatigue, soothing mood, but also reflects the human spirit is one of the important means. It not only makes students happy, but also enlightens students to cherish the time, love life, study hard. Indoor colour should be in harmony with the reading environment, bookshelves and reading the table should adopt the cool colours so that students 
read against the psychological. Indoor facilities should be placed to facilitate the main readership that is student-oriented to be bright and generous, fully equipped to enable students to learn in a free and relaxed environment. In addition, the overall indoor environment should be quiet, elegant, relaxed and comfortable, the students exposure to which can feel the full range of environmental and human affinity to consciously restrain them to participate in maintaining a good public environment, thereby enhancing their public Ethical conduct.

First, we should implement an equal service model, to change the current teachers and researchers as the main body of the service can enjoy the "privilege" of inequality. The spirit of equality is an important connotation of the humanistic spirit, but also the concrete manifestation of humanistic care. We should attach importance to the existence of the student-oriented readership and regard it as the main body of the service. The recognition of the subjective status of the reader and the respect for the subjectivity of the reader are based on the confirmation of the equality of the different subjects. So that every student reader in the library to enjoy equal access to internal rights, foreign rights, the right to purchase books and management, supervision. At the same time, because the student reader is in the position of the weak information, the library should provide individualized service for the students according to the individual information resources, establish the personalized service platform, confirm that each student in the personalized service platform System of equal status. Take the initiative to help students to collect, sort out the information required by different periods of time, and timely and effective feedback. So that each student can according to their own habits, interests, hobbies and their corresponding information needs to make equal use of this service. Library should not treat all students with differentiated and artificial restrictions, and strive to create a humane, full respect for the personality of students, warm, equal cultural environment, to achieve real equality of services, so that students receive a Kind of be respected, concerned about and being warm feeling of care. The second is to enhance the librarian's own humanistic spirit. Librarians' cultural accomplishment and professional ethics determine whether they can construct a reasonable and scientific library service model of humanistic care. Librarians are noble, elegant, knowledge of the communicator, is the symbol of civilization. In a sense, they can achieve the same effect as books. Therefore, librarians should not only have a broad library of professional knowledge, should also have the knowledge of other related disciplines. At the same time to have a strong self-confidence and a strong sense of personal efficacy. To adapt to the development of different disciplines of knowledge to improve the ability of self-learning, good at adjusting the professional attitude; have a strong will and a good role in adaptability, hardworking, optimistic and calm to face some problems; to be able to positive, of the emotional quality of state into the work. 


\section{Conclusion}

Under the premise of promoting harmonious society, it is the mission of university to cultivate the spirit of advocating morality, advocating good and advocating truth. The university library, as an integral part of the university education, is inextricably linked with the students. It is not only a process of cultural transmission, cultural inheritance and cultural creation, but also a process from the objective value to the individual The Transformation of Subjective. With the rapid development of science and technology information, the humanistic spirit and potentiality of university library service is to release the creativity and potential of library librarians, and combine the science and technology with the humanities to create the university books with humanistic spirit.

\section{References}

[1] Zhou Dai. Library Reader Service Calls for Humanistic Spirit. Library, 55(12), pp.68-70, 2011

[2] Guo Shaoquan. The modern humanistic orientation and value of library science.Sichuan Library Journal, 8 (5), pp.87- 91, 20013

[3] Yi Shuying. University library how to serve the education of correspondence. Library, 12(10), pp. 18-20, 2012

[4] Ye Lan. The contemporary value orientation of China's education bias. Educational Research, 9(6), pp.58- 61, 2011

[5] Jiang Jianlin. Chinese library humanistic spirit of the review. Library, 8(4), pp.85-87, 2014 